\title{
O Caso Ganimedes
}

Hernani Guimarães ${ }^{1}$

1 Belo Horizonte 1986. Artista Visual e pesquisador. Sua pesquisa atual parte da arte como metodologia para desvendar os diversos sentidos e potenciais da imagem no atual contexto de hiperconexão. Graduado em Pintura e desenho pela Escola Guignard (UEMG) em 2012. Mestre em Artes Visuais com ênfase em Poéticas Visuais pelo Instituto de Artes da UFRGS em 2017. Atualmente doutorando no Instituto de Artes da UERJ. Universidade do Estado do Rio de Janeiro (PPGArtes/UERJ). E-mail: hernaniguimaraesbh@ gmail.com. ORCID: https://orcid.org/0000-0001-5659-2269. Lattes iD: http://lattes.cnpq.br/3075025705902911. Rio de Janeiro, Brasil 


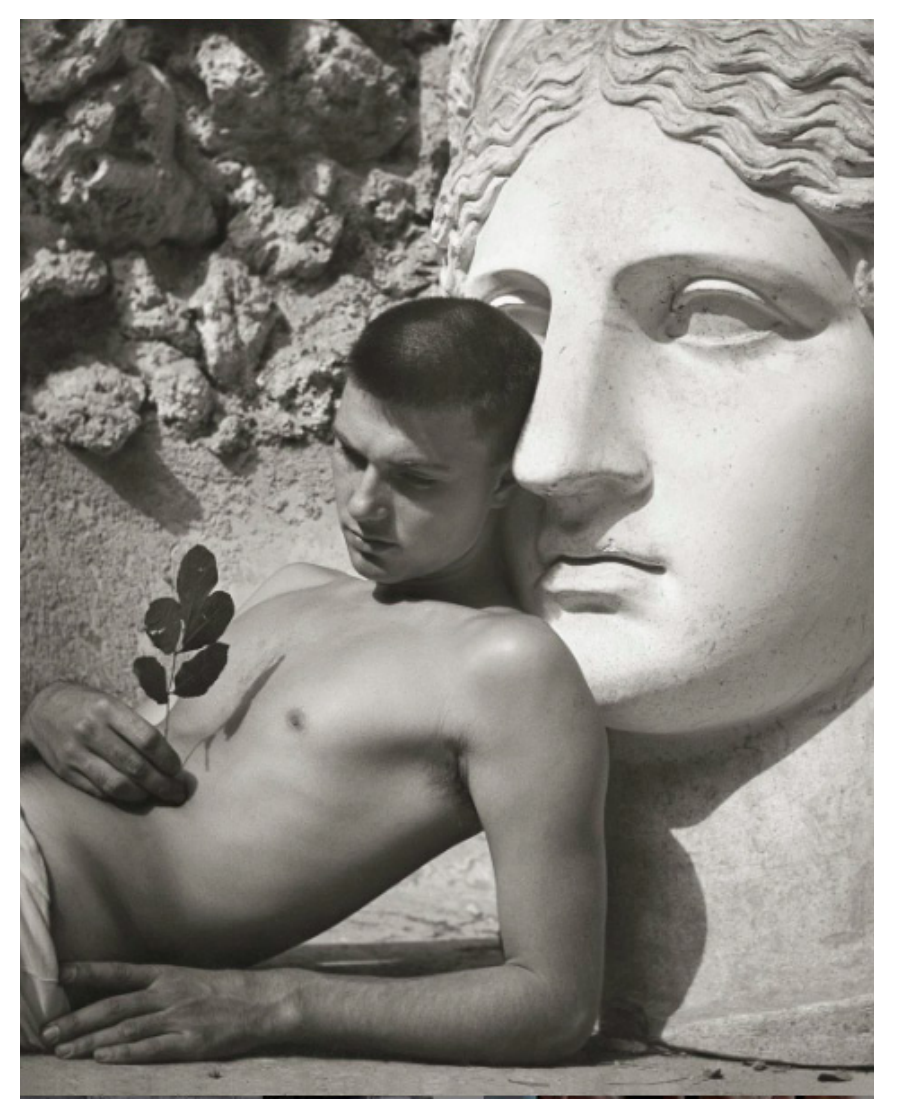



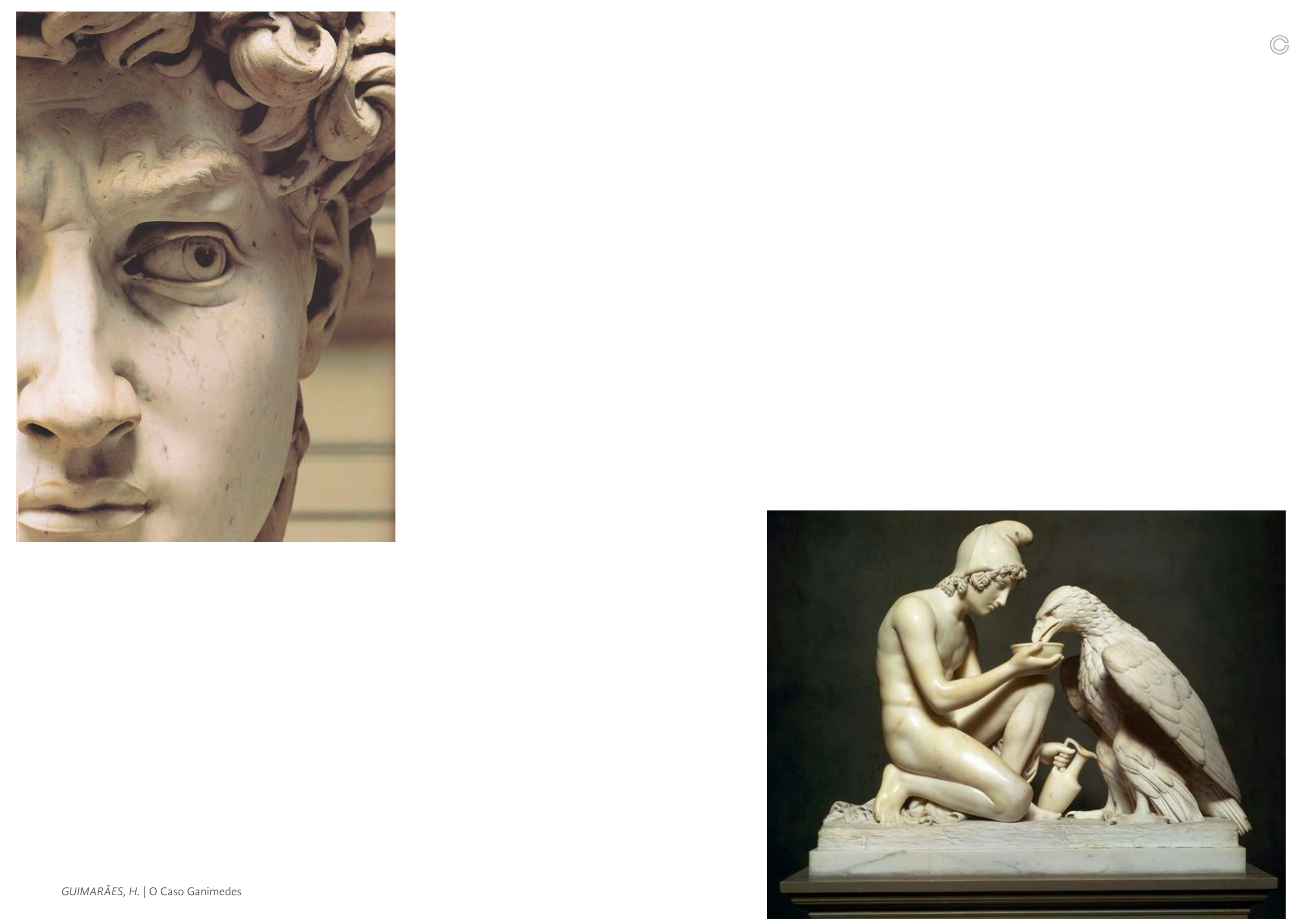

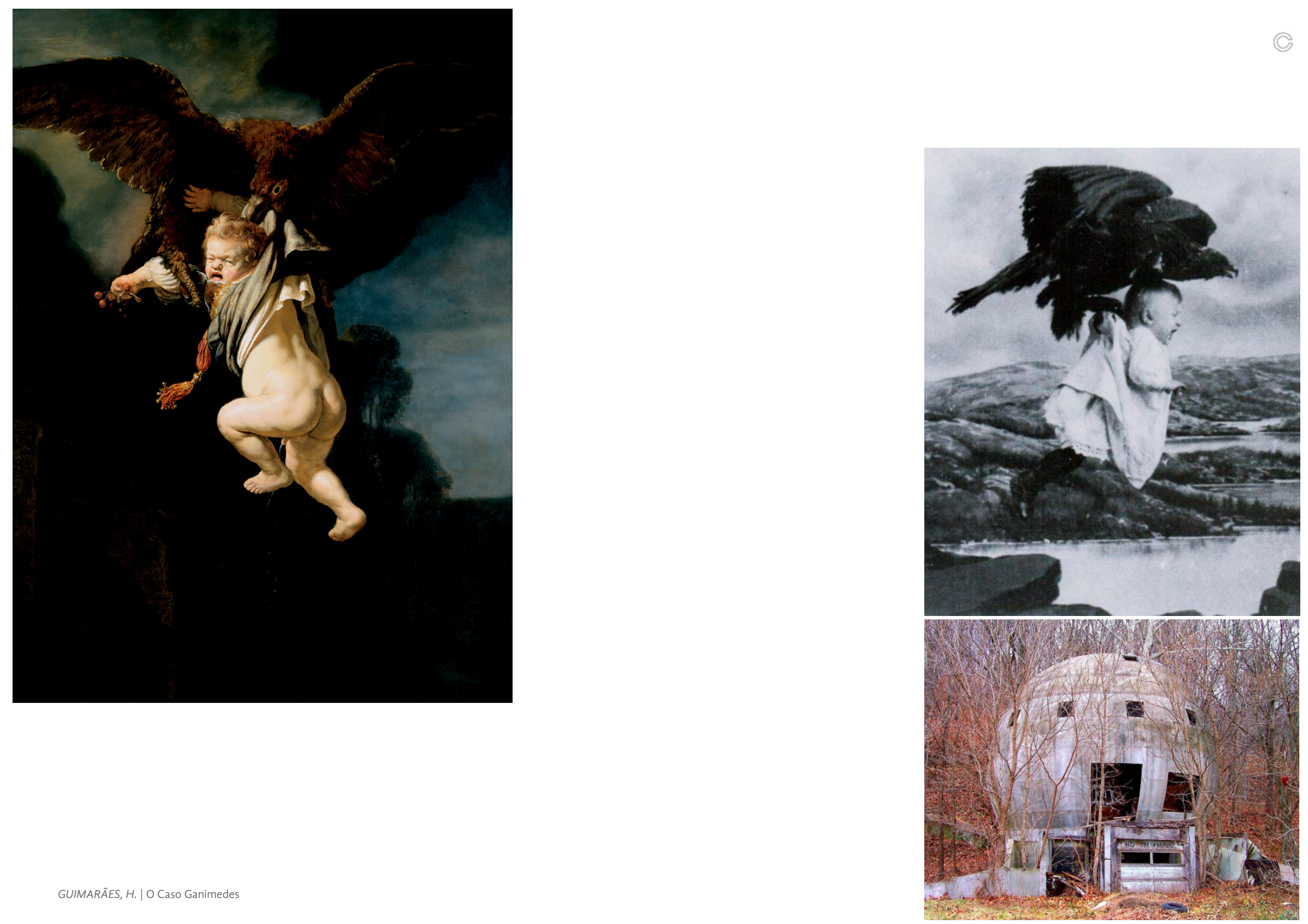

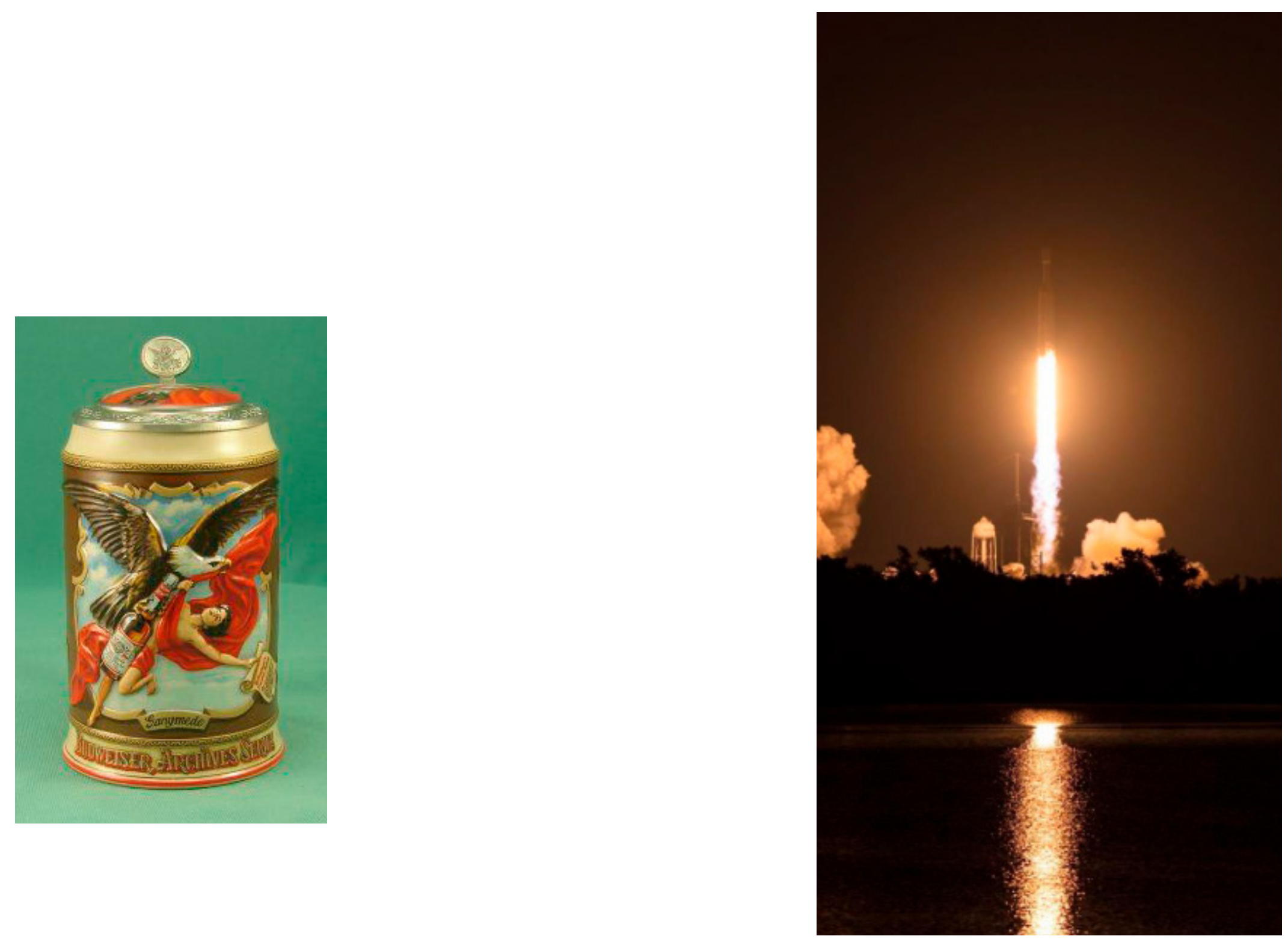

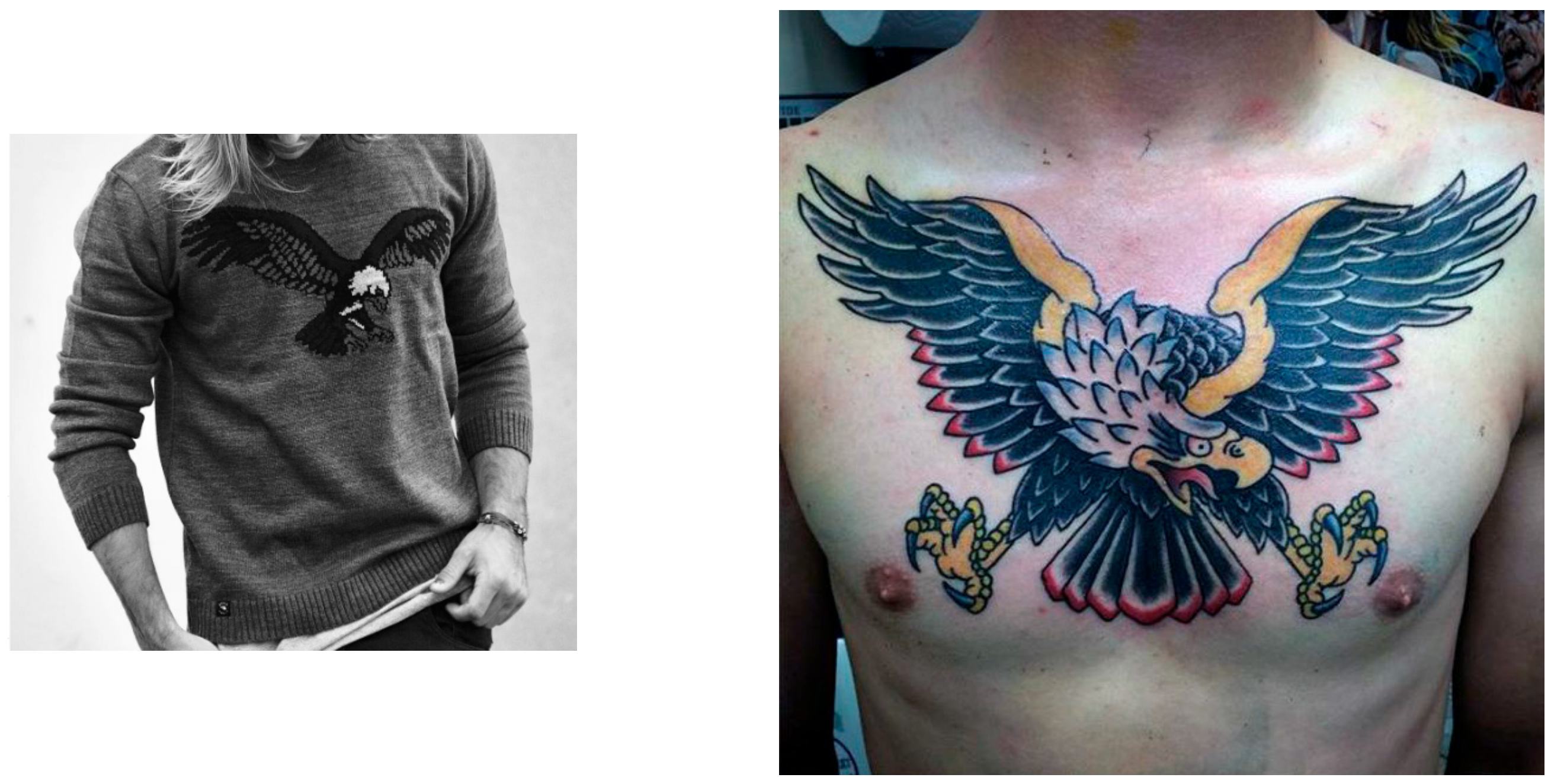

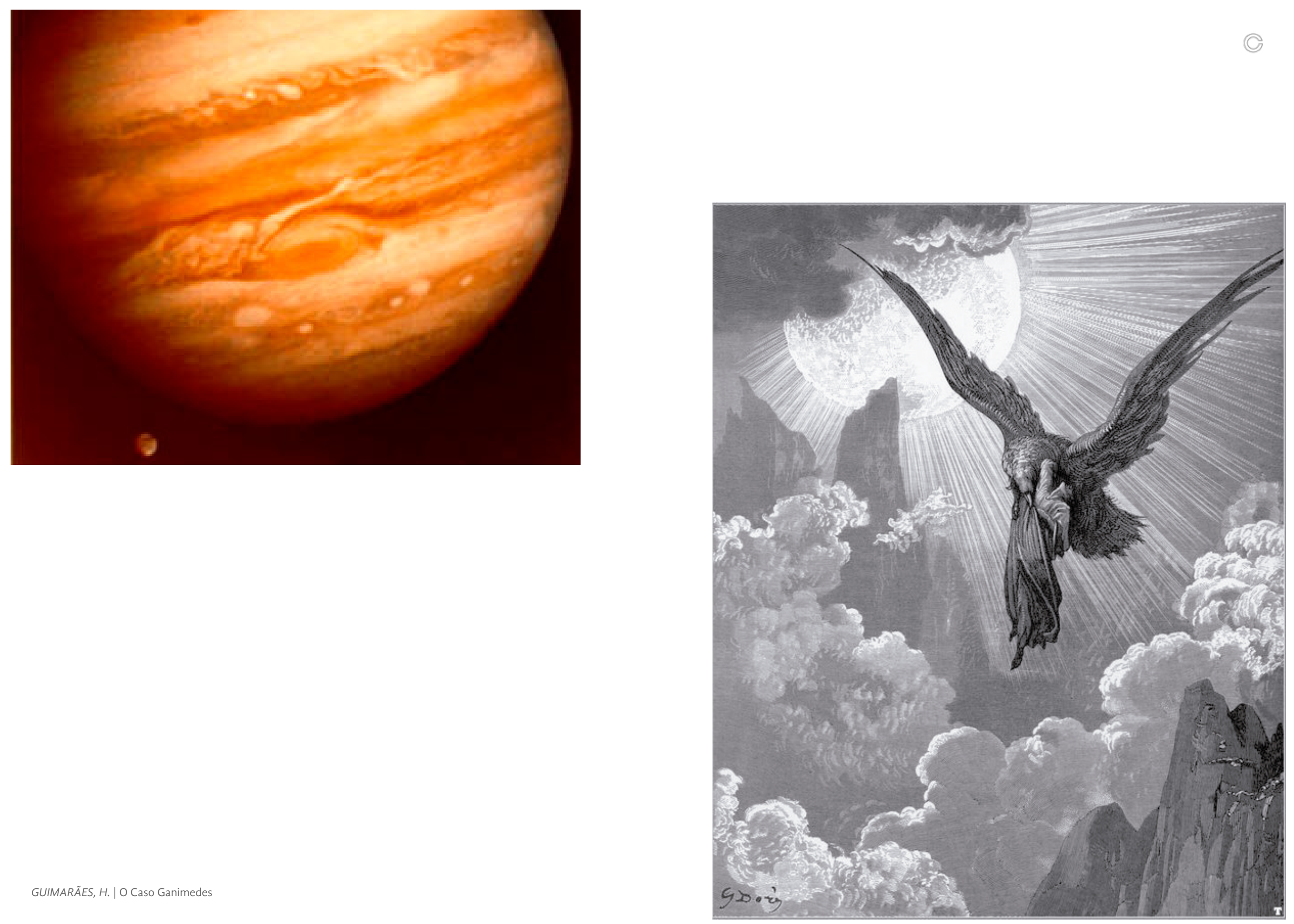

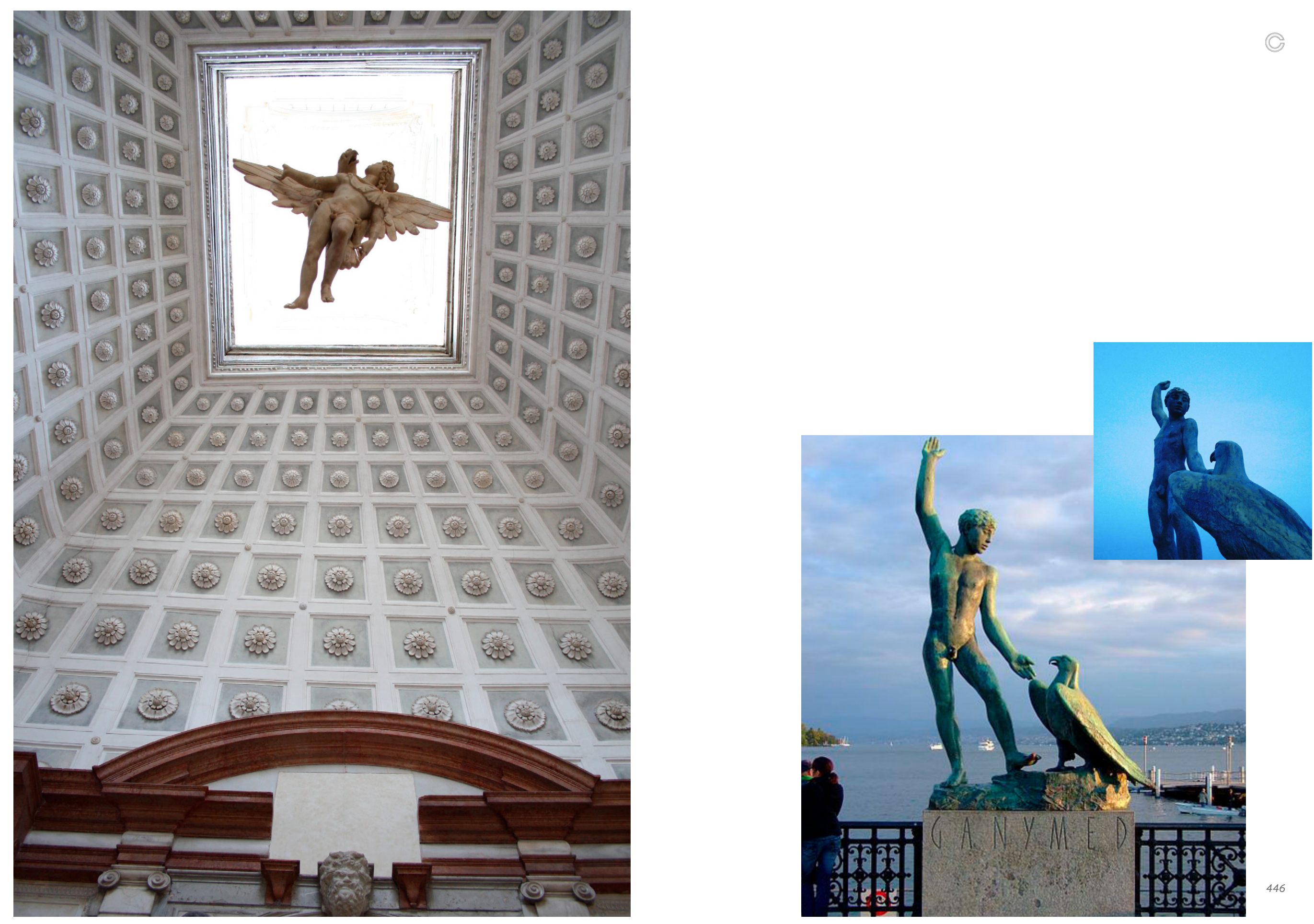

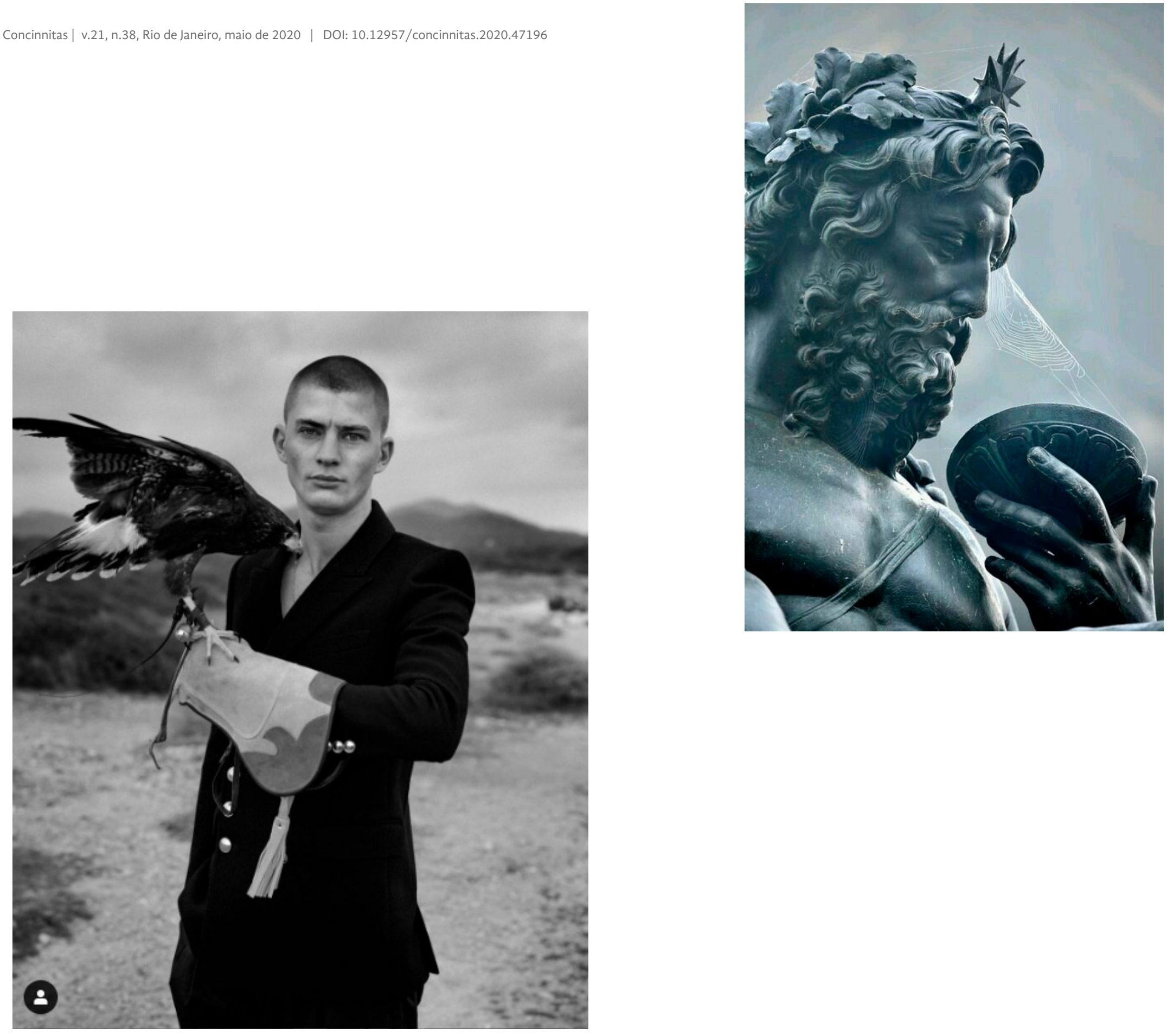

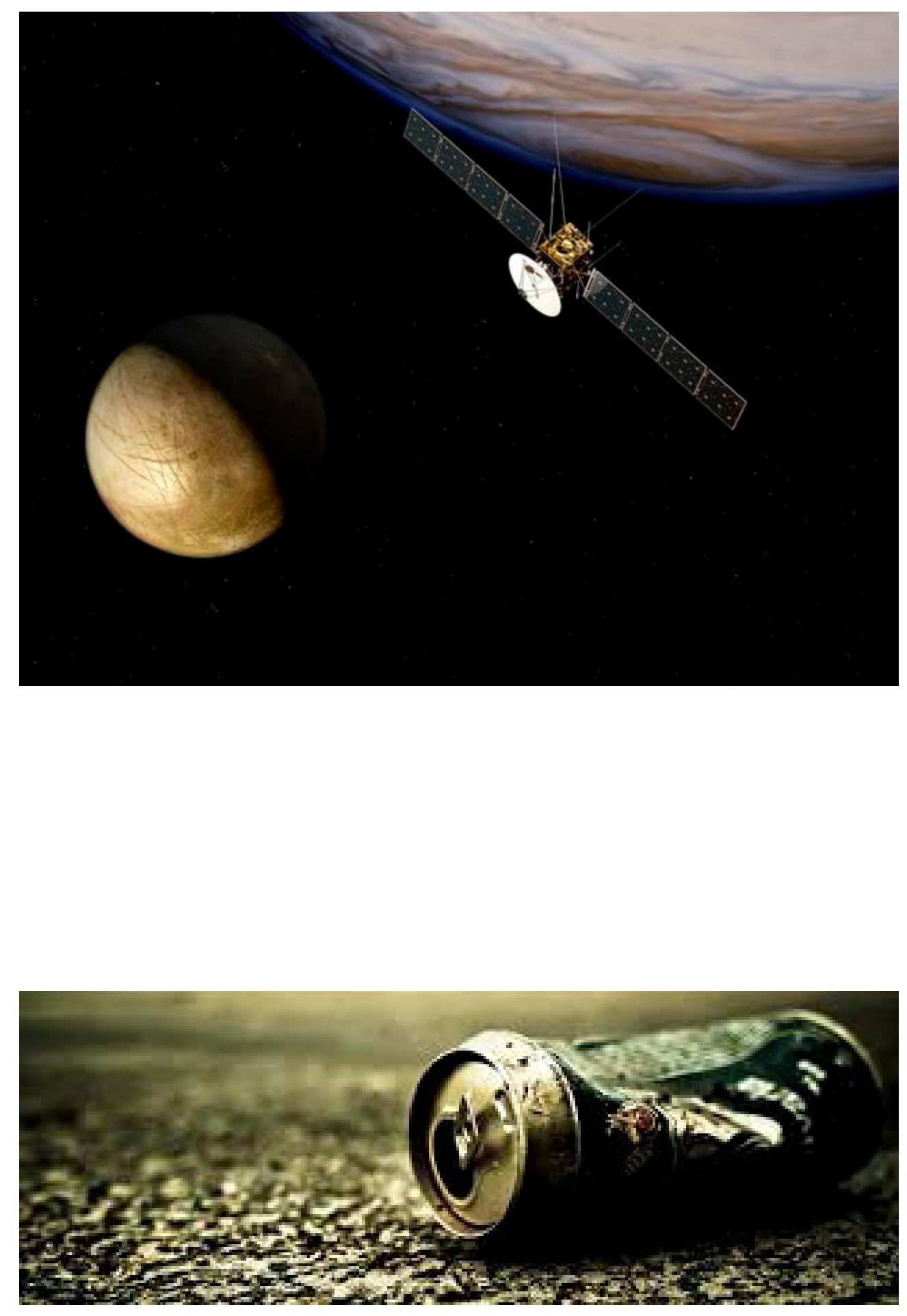

Recebido em 10 de dezembro de 2019 e aceito em 10 de março de 2020. Este é um artigo publicado em acesso aberto sob uma licença Creative Commons (cc) $\mathbf{E Y}$ 